\title{
SISTEM PENGENDALI SUHU DAN KELEMBAPAN TANAH BILIK TANAMAN SELADA BERBASIS IOT MENGGUNAKAN APLIKASI WHATSAPP
}

\author{
Toto Supriyanto ${ }^{1}$, Aminah Fiani' ${ }^{2}$, Hanna Maulidja Ulfa ${ }^{3}$ \\ 1,2,3 Jurusan Teknik Elektro, Program Studi Telekomunikasi, Politeknik Negeri Jakarta \\ Jalan Prof. DR.G.A.Siwabessy, Kampus Baru UI, Depok 16425 \\ e-mail: toto.supriyanto@elektro.pnj.ac.id',aminah.fiani.te18@mhsw.pnj.ac.id ${ }^{2}$, \\ hanna.maulidjaulfa.te18@mhsw.pnj.ac.id
}

\begin{abstract}
Lettuce is one type of vegetable plant that is easy to cultivate and can thrive optimally at a temperature of $25^{\circ} \mathrm{C}-28^{\circ} \mathrm{C}$ and $65 \%-78 \%$ soil moisture. Constraints of limited land owned make it difficult to cultivate lettuce. Plant booths are an alternative solution to these problems. Plant booths are made like terraced rooms containing an array of shelves filled with soil for growing lettuce. This system uses Arduino Uno, DHT22 temperature sensor, YL69 soil moisture sensor, LCD, DC fan, solenoid valve, and raspberry pi. The results of system testing, when the temperature value detected by the DHT22 sensor is greater than $28^{\circ} \mathrm{C}$, the system automatically activates the fan to cool the chamber, and when the temperature reaches less or equal to $25^{\circ} \mathrm{C}$, the fan automatically turns off. For the value of soil moisture, when the YL69 sensor is less or equal to $65 \%$, the system automatically waters the plants and when the soil moisture is greater than or equal to $78 \%$, the system stops watering the plants. All sensor conditions are displayed on the $16 \times 2$ I2C LCD. For the whatsapp application test results, when the owner sends the "check plants" command, the system successfully sends notifications of the state of the booth such as temperature, soil humidity, fan and whether the system is watering the plants or not.
\end{abstract}

Keywords: arduino uno, booth, lettuce, raspberry pi, whatsapp

\begin{abstract}
ABSTRAK
Selada merupakan salah satu jenis tanaman sayuran yang mudah untuk dibudidaya dan dapat tumbuh subur dengan optimal pada suhu $25^{\circ} \mathrm{C}-28^{\circ} \mathrm{C}$ dan kelembapan tanah $65 \%-78 \%$. Kendala keterbatasan lahan yang dimiliki menyebabkan sulitnya melakukan budidaya tanaman selada. Bilik tanaman adalah alternatif solusi untuk permasalahan tersebut. Bilik tanaman dibuat seperti ruangan bertingkat yang berisi susunan rak yang diisi tanah untuk menanam selada. Sistem ini menggunakan arduino uno, sensor suhu DHT22, sensor kelembapan tanah YL69, LCD, kipas DC, solenoid valve, dan raspberry pi. Hasil pengujian sistem, saat nilai suhu yang terdeteksi oleh sensor DHT22 lebih besar sama dengan $28^{\circ} \mathrm{C}$ maka sistem secara otomatis mengaktifkan kipas untuk mendinginkan bilik, dan saat suhu mencapai kurang atau sama dengan $25^{\circ} \mathrm{C}$ kipas secara otomatis mati. Untuk nilai kelembapan tanah, saat sensor YL69 kurang atau sama dengan $65 \%$ maka sistem secara otomatis menyiram tanaman dan saat kelembapan tanah lebih besar atau sama dengan $78 \%$ maka sistem berhenti menyiram tanaman. Semua kondisi sensor tersebut ditampilkan pada LCD I2C 16×2. Untuk hasil pengujian aplikasi whatsapp, saat pemilik mengirimkan perintah "cek tanaman", maka sistem berhasil mengirimkan notifikasi keadaan bilik seperti suhu, kelembapan tanah, kipas dan apakah sistem sedang menyiram tanaman atau tidak.
\end{abstract}

Kata kunci: arduino uno, bilik, raspberry pi, selada, whatsapp 


\section{PENDAHULUAN}

Selada merupakan salah satu jenis tanaman sayuran yang mudah untuk dibudidayakan di Indonesia dengan pertumbuhan yang cepat, sehingga banyak orang yang melakukan budidaya tanaman ini untuk dijadikan peluang usaha ataupun untuk dikonsumsi [1]. Selada akan tumbuh optimal pada rentang suhu udara $25^{\circ} \mathrm{C}$ sampai $28^{\circ} \mathrm{C}$ dan kelembapan tanah $65 \%$ sampai $78 \%$ [2]. Pada daerah perkotaan, terdapat kendala keterbatasan lahan untuk melakukan budidaya tanaman salada. Diperlukan suatu alternatif untuk dapat berbudidaya tanaman ini pada lahan yang sempit yaitu menggunakan bilik tanaman. Bilik tanaman adalah sebuah ruang dengan susunansusunan terdiri dari rak-rak yang diisi dengan tanah yang digunakan untuk menanam salada. Dengan menggunakan bilik tanaman seperti ini tetap dapat melakukan budidaya tanaman salada. Bilik tanaman ini dilengkapi suatu sistem yang dapat mengontrol keadaan suhu dan kelembapan tanah berbasis Internet of things (IoT).

IoT adalah kemajuan teknologi yang membantu komunikasi antara satu perangkat dengan perangkat yang lain menggunakan jaringan internet sebagai penghubung. Selama terhubung dengan jaringan internet, perangkat IoT dapat diakses dan digunakan kapan dan dimana saja [3]. IoT memiliki peran dalam pengiriman data jarak jauh melalui komputer yang terkoneksi ke jaringan internet. Melalui internet dapat berbagi data, remote control, dan berbagai hal lainnya. IoT bekerja dengan menerjemahkan bahasa pemrograman yang sudah dimasukkan ke dalam mikrokontroler. Adanya IoT sebagai sistem kontrol pada perangkat memudahkan komunikasi sehingga menjadi lebih cepat dan mudah.

Salah satu pemanfaatan IoT adalah untuk melakukan pemantauan jarak jauh terhadap kondisi tanaman seperti tanaman selada, menggunakan aplikasi whatsapp. Keunggulan IoT menggunakan aplikasi whatsapp diantaranya adalah pengguna dapat memantau kondisi tanaman selada secara realtime. Penggabungan teknologi yang diterapkan pada pertanian dapat menghasilkan produk yang lebih efektif dan berdampak pada pekerjaan manusia yang menjadi lebih mudah dan cepat.

Sistem menggunakan arduino uno sebagai mikrokontroler yang terhubung dengan sensor suhu DHT22 dan sensor kelembapan tanah YL69 [4],[5],[6]. Keadaan suhu dan kelembapan akan ditampilkan pada display LCD. Sistem juga dilengkapi raspberry pi sebagai pengendali untuk menjalankan program dan memberikan perintah respon pada twilio [7]. Raspberry pi menerima respon arduino dan meneruskannya ke twilio sebagai antarmuka untuk memberikan notifikasi berupa suhu dan kelembapan bilik tanaman melalui aplikasi whatsapp. Aplikasi whatsapp juga dapat mengirim perintah untuk mengecek keadaan tanaman pada bilik.

Pada saat nilai suhu yang terdeteksi oleh sensor DHT22 lebih besar atau sama dengan $28^{\circ} \mathrm{C}$ maka sistem secara otomatis akan mengaktifkan kipas untuk mendinginkan ruangan. Jika suhu kurang atau sama dengan $25^{\circ} \mathrm{C}$ maka sistem secara otomatis mematikan kipas. Pada saat nilai kelembapan tanah yang terdeteksi oleh sensor YL69 kurang atau sama dengan 65\% maka sistem akan otomatis mengaktifkan solenoid valve untuk menyiram tanaman. Dan jika kelembapan tanah lebih besar atau sama dengan 78\%, maka sistem secara otomatis menonaktifkan solenoid valve sehingga air berhenti mengalir [8]-[10].

\section{METODE PENELITIAN}

Metode penelitian diawali dari perancangan hardware, pemrograman sistem dengan arduino uno, dan pemrograman untuk notifikasi aplikasi whatsapp. Sebelum dilakukan perancangan hardware perlu diketahui dahulu prinsip kerja dari sistem, diperlihatkan pada Gambar 1 ilustrasi kerja sistem pengendali suhu dan kelembapan tanah bilik tanaman selada berbasis IoT.

Bilik tanaman dibentuk seperti ruangan dengan susunan rak bertingkat dua, dimana rak tersebut di isi dengan tanah dan digunakan untuk menanam selada. Pada masing-masing tingkat diletakkan sensor suhu DHT22 dan sensor kelembapan YL69. Arduino uno dihubungkan ke sensor suhu DHT22 dan sensor kelembapan tanah YL69, sebagai pengolah data. Hasil pembacaan data dari sensor-sensor tersebut ditampilkan di LCD yang diletakkan pada bagian depan bilik. Sistem juga dilengkapi kipas DC yang berfungsi untuk mendinginkan bilik jika suhu yang terbaca pada sensor DHT22 lebih besar atau sama dengan $28^{\circ} \mathrm{C}$, dan solenoid valve berfungsi untuk mengalirkan air jika kelembapan tanah yang terbaca oleh sensor YL69 kurang atau sama dengan 65\%. Bilik tanaman dilengkapi growlight LED strip agar pada ruangan yang minim sinar matahari lampu ini dapat menyinari bilik tanaman sebagai pengganti sinar matahari, sehingga tanaman selada tetap dapat tumbuh dengan baik. 


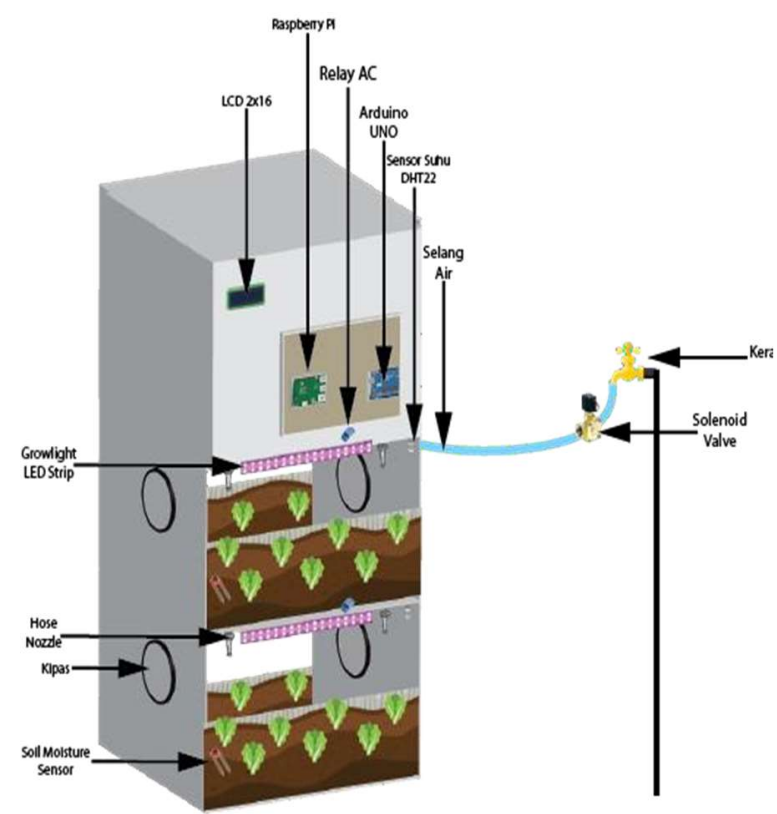

Gambar 1. Ilustrasi Kerja Sistem Pengendali Suhu Dan Kelembapan Tanah Bilik Tanaman Selada Berbasis IoT

Diagram blok dari sistem diperlihatkan pada Gambar 2, dan spesifikasi sistem pada Tabel 1.

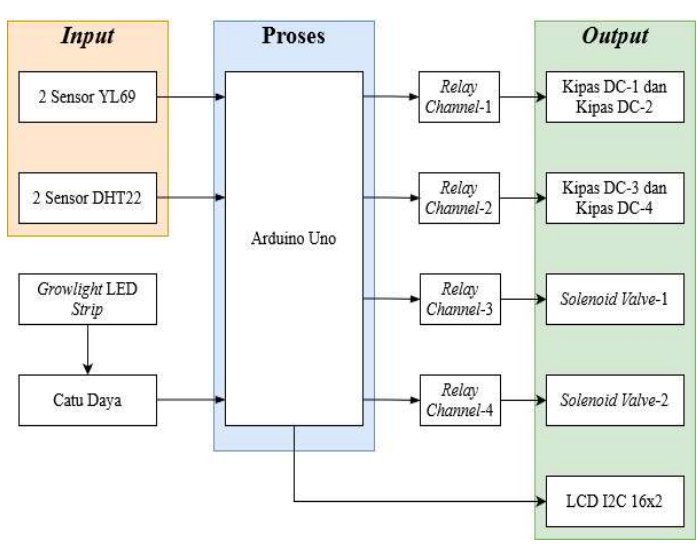

Gambar 2. Diagram Blok Sistem Pengendali Suhu dan Kelembapan Tanah Bilik Tanaman Selada

Tabel 1. Spesifikasi Sistem Bilik Tanaman

\begin{tabular}{|c|c|c|}
\hline No & Alat & Deskripsi \\
\hline 1. & Mikrokontroler & $\begin{array}{l}\text { Arduino Uno Rev 3, } \\
\text { microcontroller } \\
\text { processor: } \\
\text { ATmega328P, } \\
\text { tegangan 5V. }\end{array}$ \\
\hline 2. & Sensor suhu & $\begin{array}{l}\text { DHT22-AM2303, } \\
\text { tegangan } 3,3-6 \mathrm{~V}, \\
\text { temperature range: - } \\
40^{\circ} \sim 125^{\circ} \mathrm{C} \text {. }\end{array}$ \\
\hline
\end{tabular}

3. Sensor YL69, tegangan kelembapan operasi: $3,3-5 \mathrm{~V}$, value tanah range $\mathrm{ADC}$ : 01023 bit.

4. LCD $2 \times 16$, tegangan $5 \mathrm{~V}$.

5. Relay normally open $(\mathrm{NO}), 4$

6. Raspberry Pi Model 3b, OS berbasis linux, BCM2387, chipset 1,2GHz, dan Quad Core ARM Cortex A53 64bit

7. Arduino IDE Versi 1.8.14

8. Thonny Python Versi 3.7.9, untuk menerima respon arduino dan meneruskan program

9. Whatsapp

10. Catu daya ke twilio

Versi 2.2.0, untuk notifikasi dan memberikan perintah $12 \mathrm{~V}_{\mathrm{dc}}$

Setelah mengetahui prinsip kerja dari sistem, dilakukan perancangan hardware sistem yaitu perancangan Arduino uno, dan mikrokontroler ATMega328P berfungsi sebagai pengolah data, sensor suhu DHT22, sensor kelembapan YL69, display LCD 2x16, relay untuk kipas dan solenoid valve, dan catu daya $12 \mathrm{~V}$.

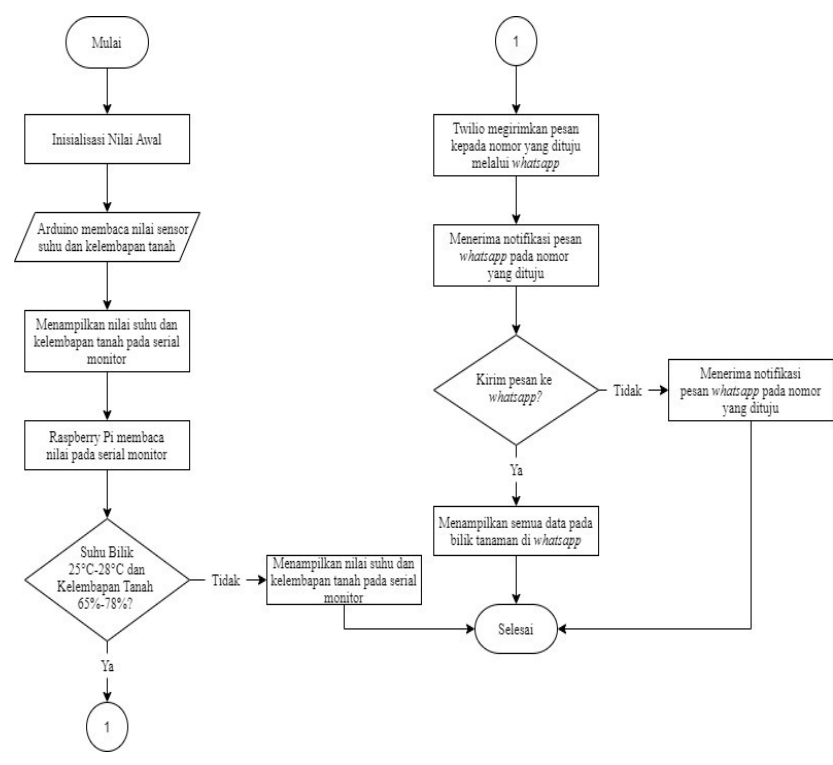

Gambar 3. Diagram alir pemrograman notifikasi dari raspberry pi ke aplikasi whatsapp menggunakan twilio

Selanjutnya dilakukan pemrograman notifikasi dari raspberry pi ke aplikasi whatsapp menggunakan twilio seperti pada Gambar 3, dan pemrograman Arduino menggunakan arduino 


\section{Sistem Pengendali Suhu dan Kelembapan Tanah}

IDE, ditunjukkan pada Gambar 4, sesuai prinsip kerja sistem yang diinginkan. Pada saat sensor DHT22 mendeteksi suhu lebih besar atau sama dengan $28^{\circ} \mathrm{C}$ maka arduino uno memberikan perintah kepada relay untuk mengaktifkan 2 buah kipas DC dengan tujuan mendinginkan ruangan, sehingga suhu pada bilik akan menjadi turun. Jika suhu sudah mencapai kurang atau sama dengan $25^{\circ} \mathrm{C}$ maka secara otomatis kipas DC akan berhenti berputar. Pada saat sensor YL69 mendeteksi kelembapan tanah kurang atau sama dengan $65 \%$ maka arduino uno memberikan perintah kepada relay untuk membuka solenoid valve sehingga air akan mengalir membasahi tanah. Jika kelembapan tanah sudah mencapai lebih besar atau sama dengan 78\% maka secara otomatis solenoid valve tertutup dan air berhenti mengalir. LCD I2C $2 \times 16$ menampilkan data suhu dan kelembapan tanah yang terbaca oleh sensor DHT22 dan sensor YL69.

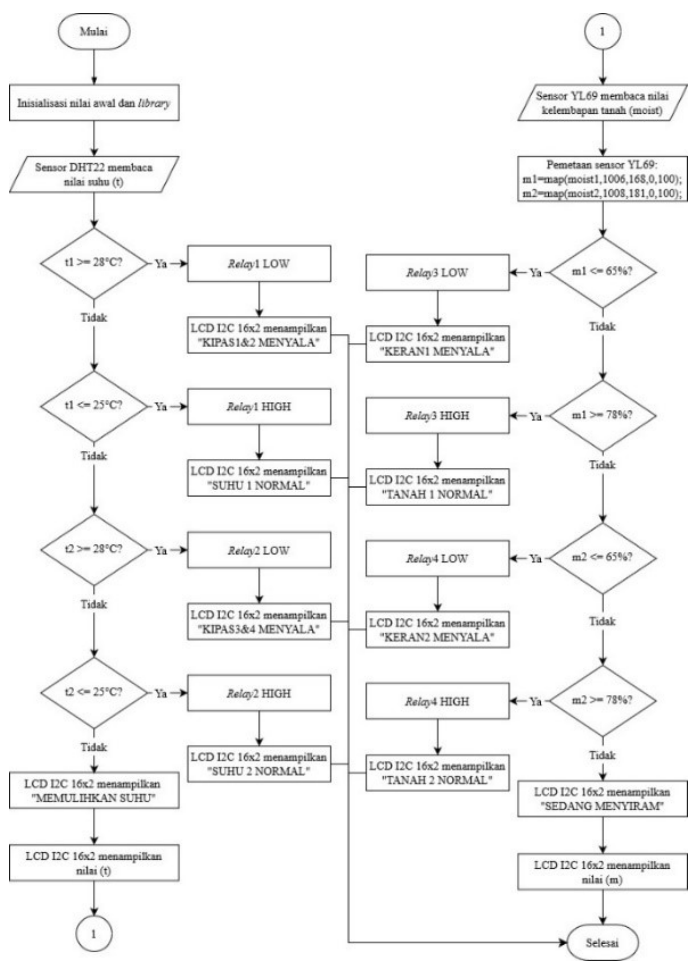

Gambar 4. Diagram alir pemrograman Sistem Pengendali Suhu dan Kelembapan Tanah

Arduino uno juga dihubungkan ke raspberry pi. Arduino uno mengirimkan data suhu dan kelembapan yang terbaca pada sensor ke raspberry pi. Raspberry pi akan memproses data tersebut dan mengirimkan ke aplikasi whatsapp berupa notifikasi suhu dan kelembapan. Aplikasi whatsapp digunakan untuk notifikasi ke pemilik berupa keadaan bilik. Pemilik dapat mengirimkan perintah dengan mengetikkan komentar "cek tanaman", sistem akan mengirimkan notifikasi berupa keadaan bilik tanaman. Notifikasi diberikan berupa suhu, kelembapan, keadaan kipas, dan juga status air keran solenoid. Pemrograman pada raspberry pi menggunakan aplikasi pemrograman thonny python, dan sebagai antarmuka antara raspberry pi ke whatsapp menggunakan twilio.

\section{HASIL DAN PEMBAHASAN}

Hasil perancangan rangkaian keseluruhan sistem diperlihatkan pada Gambar 5, dimana rangkaian mikrokontroler sudah terintegrasi dengan sensor-sensor dan LCD.

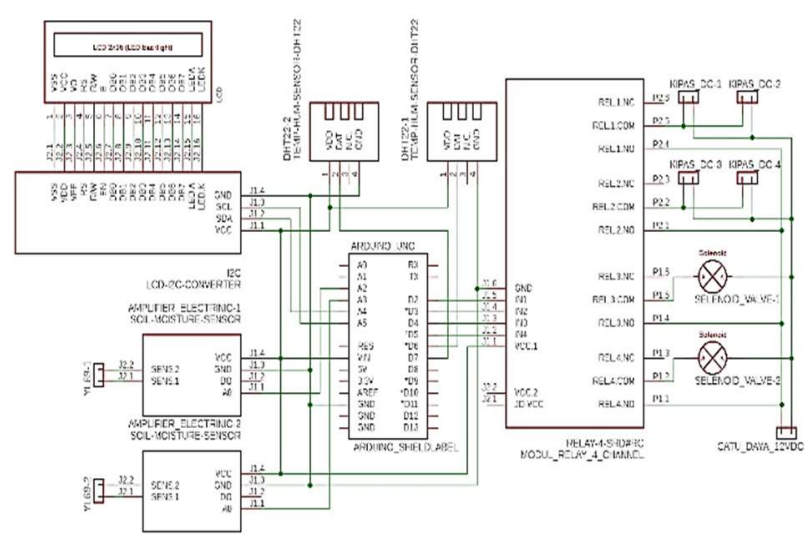

Gambar 5. Rangkaian Keseluruhan Sistem Bilik tanaman

Gambar 6 memperlihatkan komunikasi serial hubungan raspberry pi dengan Arduino uno.

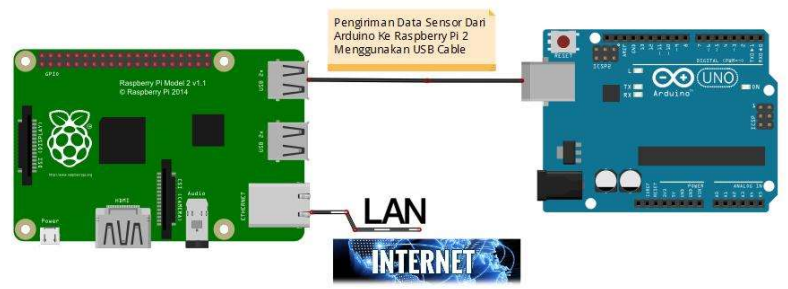

Gambar 6. Komunikasi serial hubungan raspberry pi dengan Arduino uno

Dari hasil pengujian sensor suhu DHT22, jika suhu dicapai lebih besar atau sama dengan $28^{\circ} \mathrm{C}$, maka secara otomatis sistem akan mengaktifkan kipas angin agar suhu ruangan dapat turun kurang dari $28^{\circ} \mathrm{C}$. Pada saat suhu sudah turun secara otomatis kipas akan off. Suhu berhasil juga ditampilkan pada display LCD. Selain itu sistem berhasil mengirimkan notifikasi ke whatsapp. Hasil ini sesuai dengan perancangan yang diinginkan, baik dari segi perancangan hardware dan pemrograman Arduino uno. 
Untuk pembacaan sensor kelembapan YL69, pada saat kelembapan kurang atau sama dengan $65 \%$, secara otomatis sistem mengaktifkan solenoid valve sehingga air akan mengalir menyiramkan tanaman. Saat kelembapan mencapai nilai $78 \%$ atau lebih besar, solenoid valve akan secara otomatis off dan berhenti menyiram tanaman. Tingkat kelembapan tanah juga berhasil di tampilkan di LCD dan dikirim sebagai notifikasi ke aplikasi whatsapp. Pengujian suhu dan kelembapan berhasil dilakukan pada 2 tingkat rak bilik tanaman, dimana masing-masing tingkat memiliki 2 kipas DC dan 1 solenoid valve untuk menyiram tanaman.

Untuk pengujian aplikasi whatsapp dilakukan dengan memberikan perintah sesuai dengan pemrograman. Program python yang telah dibuat berisikan perintah yang ditampilkan di aplikasi whatsapp dengan menggunakan kata kunci yang sudah ditentukan. Pada saat pemilik ingin mengetahui kondisi bilik tanaman dapat dilakukan dengan menuliskan "cek tanaman" dan dikirimkan ke sistem. Secara otomatis sistem berhasil merespon perintah ini dan menjawab dengan "Hello! Mau cek tanaman seladamu?", sesuai yang telah diprogram.

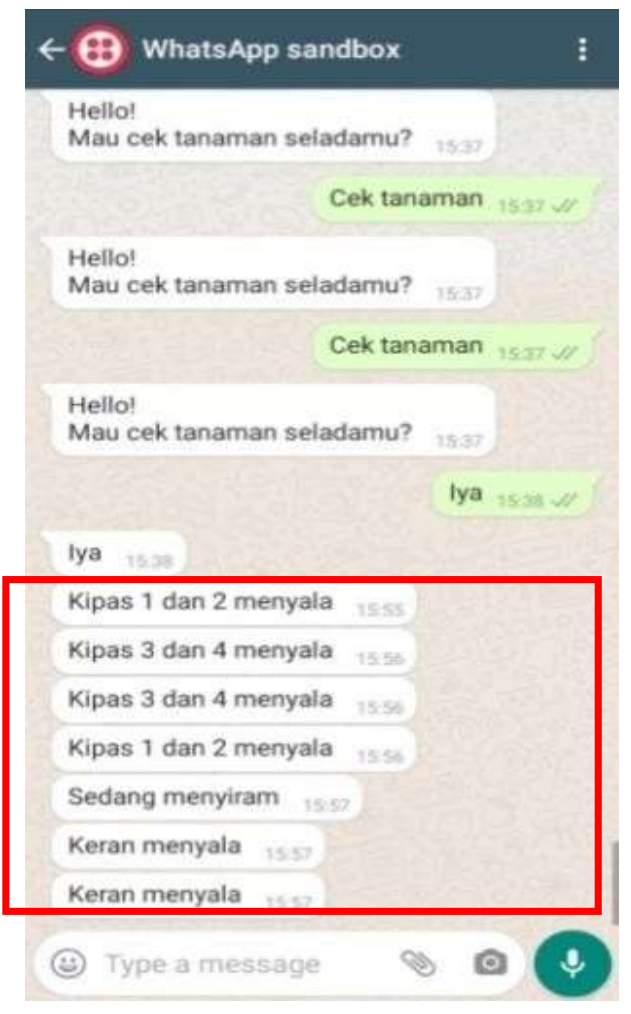

Gambar 7 Tampilan Hasil pengujian 2 arah Pesan Whatsapp

Gambar 7 memperlihatkan hasil komunikasi 2 arah dari aplikasi whatsapp antara pemilik dan sistem, sesuai dengan yang telah diprogram. Saat pemilik ingin mengetahui keadaan bilik, maka mengetikkan perintah "cek tanaman", sistem mengirimkan berita kipas menyala, sedang menyiram, dan keran menyala. Ini artinya pada saat dilakukan keadaan tersebut suhu pada bilik lebih atau sama dengan $28^{\circ} \mathrm{C}$, sehingga kipas menyala. Sedangkan kelembapan kurang dari $65 \%$, sehingga keran atau solenoid valve terbuka untuk menyiramkan air agar kelembapan tanah tercapai antara $65 \%-78 \%$.

\section{KESIMPULAN}

Berdasarkan hasil pengujian Sistem Pengendali Suhu dan Kelembapan Tanah Bilik Tanaman Selada Berbasis IoT Menggunakan Aplikasi Whatsapp, sensor suhu DHT22 dan sensor kelembapan YL69 dapat berfungsi sesuai perancangan yang diinginkan. Saat suhu bilik mencapai $28^{\circ} \mathrm{C}$ atau lebih besar, secara otomatis kipas DC pada bilik aktif untuk mendinginkan ruangan, dan secara otomatis juga berhenti berputar saat suhu sudah kembali dibawah atau sama dengan $25^{\circ} \mathrm{C}$. Untuk kelembapan, pada saat sensor kelembapan membaca kelembapan tanah pada bilik mencapai kurang atau sama dengan $65 \%$, secara otomatis sistem mengaktifkan solenoid valve dan air mengalir menyiram selada dan tanah. Saat kelembapan tanah mencapai 78\% atau lebih, solenoid valve otomatis tertutup kembali dan air berhenti mengalir. Status pembacaan sensor-sensor berhasil ditampilkan pada display LCD 2x16 yang diletakkan di depan pintu bilik.

Untuk pengujian aplikasi whatsapp dilakukan dengan mengirimkan perintah "cek tanaman". Sistem berhasil merespon dan mengirimkan balasan berupa notifikasi keadaan kipas sedang menyala atau mati. Termasuk memberikan respon keadaan solenoid valve terbuka berarti sedang menyiram tanaman, saat kelembapan tanah dibawah $65 \%$, dan saat kelembapan mencapai $78 \%$ solenoid valve tertutup, air berhenti mengalir. Secara keseluruhan berarti sistem sudah berfungsi dengan baik sesuai dengan perancangan, baik secara hardware dan pemrograman.

\section{DAFTAR PUSTAKA}

[1] Kase, Abigail. J, Teknik Budidaya Selada.

http://cybex.pertanian.go.id/mobile/artik el/81210/Teknik-Budidaya-Selada/, 5 juni 2021.

[2] Darmawan I. A, Pengaruh Topoklimat terhadap produksi dan Kualitas Selada, 
skripsi, Universitas Gadjah Mada, Yogyakarta, 1997.

[3] [3] T. Changmai, S. Gertphol and P. Chulak, Smart Hydroponic Lettuce Farm using Internet of Things, 10th International Conference on Knowledge and Smart Technology (KST), IEEE, 2018, pp. 231-236.

[4] Anggara. Bayu Tri, Sistem Pengukur Kelembaban Tanah Pertanian Dan Penyiraman Otomatis Berbasis Internet of Thngs (IoT), Jurnal Teknik Informatika, Universitas Islam Majapahit, 2018, pp. 3

[5] Lubis. Herdian Rizaldy, Rancang Bangun Smart Sistem Ruang Greenhouse Berbasis Iot Dengan Menggunakan Arduino Uno, Skripsi, Jurusan Teknik Elektro Fakultas Teknologi Industri Universitas Islam Indonesia Yogyakarta, 2020.

[6] Sinauarduino, Mengenal Arduino Software (IDE). https://www.sinauarduino.com/artikel/ mengenal-arduino- software-ide/, 5 juni 2021

[7] DevicePlus Editorial Team, How to Run Arduino Sketches on Raspberry pi. https://www.deviceplus.com/raspberrypi/how-to-run-arduino-sketches-onraspberry-pi/, 30 Juni 2021

[8] Setiawati. Irene, Harsono. Budi, Sistem Hidroponik Berbasis Internet Of Things Jurnal Dielektrika, P-ISSN 2086-9487, E-ISSN 2579-650x, Vol. 7, No.2, Agustus 2020, pp. 82 -87.

[9] Jupri, Achmad, and Abdul Muid. " Rancang bangun alat ukur suhu, kelembaban, dan ph pada tanah berbasis mikrokontroler ATMega328P." JEPIN (Jurnal Edukasi dan Penelitian Informatika) 3.2 (2017): 76-81.

[10] Kharisma, Mila, Iwan Sugriwan, and Ade Agung Harnawan. " Pembuatan Alat Ukur Multi Kanal Kelembaban Tanah Berbasis Mikrokontroler Arduino Uno." Jurnal Fisika Flux: Jurnal Ilmiah Fisika FMIPA Universitas Lambung Mangkurat 1.1 (2019): 107-111. 